\title{
SPL Race Terminology
}

National Cancer Institute

\section{Source}

National Cancer Institute. SPL Race Terminology. NCI Thesaurus. Code C107675.

Terminology used for representation of the race designation in the framework of the Structured Product Labeling documents. 